\title{
Experimental Investigation of the Formation of Rockburst Pits in Circular Tunnel Based on CT Scanning
}

\author{
Peng Liang, Yanbo Zhang $\mathbb{D}^{D}$, Xulong Yao, Lin Sun, and Baozhu Tian \\ School of Mining Engineering, North China University of Science and Technology, Tangshan 063210, Hebei, China \\ Correspondence should be addressed to Yanbo Zhang; fzdn44444@163.com
}

Received 12 August 2020; Revised 3 September 2020; Accepted 21 September 2020; Published 8 October 2020

Academic Editor: Fengqiang Gong

Copyright (C) 2020 Peng Liang et al. This is an open access article distributed under the Creative Commons Attribution License, which permits unrestricted use, distribution, and reproduction in any medium, provided the original work is properly cited.

\begin{abstract}
The rockburst simulation experiments of granite samples with a circular hole under biaxial loading were conducted, and the samples were scanned by computed tomography (CT) at the end of experiment. Through a series of CT images, the failure characteristics of the circular hole wall were analysed to determine the types of rockburst pits, and the detailed formation process of different types of rockburst pits was studied in combination with the crack characteristics around them. The experimental results indicate that there are mainly two types of rockburst pits, namely, pan-shaped and V-shaped, which can occur symmetrically or asymmetrically on the left and right sidewall of the circular hole. The formation of rockburst pits is related to the cracks parallel and perpendicular to the principal stress. Cracks parallel to the principal stress can determine the depth of the rockburst pit and affect the type of the rockburst pit, and cracks perpendicular to the principal stress determine the width of the rockburst pit. There is a correlation between the formation process of pan and V-shaped rockburst pits. During the formation of a V-shaped rockburst pit, several rockbursts occur, and each rockburst forms a pan-shaped rockburst pit. In the process of developing from the tunnel wall to the deep rock, the width of the pan-shaped rockburst pit gradually decreases and a V-shaped rockburst with a stepped upper and lower boundary is formed.
\end{abstract}

\section{Introduction}

A rockburst is a common dynamic instability disaster encountered in the process of underground engineering excavation under high ground stress environments: the surrounding rock is suddenly ejected into the excavation space, which directly threatens the safety of construction personnel and equipment, and has become a bottleneck problem restricting the safe construction of deep underground engineering works [1]. It is of theoretical and practical significance to study the mechanism of rockbursts. When a rockburst occurs, rockburst pits will be formed on the tunnel wall. The formation process of rockburst pits is directly related to the stress regime, and the intensity or grade of rockbursting. Therefore, studying the detailed formation process of rockburst pit is helpful to reveal the intangible evolution of a tunnel rockburst, and it is of importance to clarify the mechanism of occurrence of roadway rockbursts.
In the process of exploring the mechanism of rockburst, scholars attach great importance to the study of rockburst pits. Feng et al. [2] pointed out that shallow pit-shaped, deep pit-shaped, and V-shaped rockburst pits will be formed after real-time rockbursts when analysing the shape of rockburst formed during the excavation of a deeplyburied tunnel. Chen et al. [3] found that a shallow $\mathrm{V}$-shaped rockburst pit was formed after a typical timedelay rockburst in the diversion tunnel of Jinping II Hydropower Station. Zhang and Ma [4] analysed the rockburst failure characteristics of the diversion tunnel of the Jinping II Hydropower Station. After the rockburst, rockburst pits of different sizes and shapes were formed, including trough, pot bottom, dome, and irregular shapes. Liu et al. [5] investigated the rockbursts in Kamchik Tunnel in Uzbekistan and found that the rockburst pits were large underneath and small on top. In simulation experiment, Lee and Haimson [6] found that a V-shaped fracture occurred in the wall of the rock containing a circular hole 
under biaxial compression. Gong et al. [7] conducted rockburst tests on a sample containing a circular tunnel model and found that strain rockbursts occur on both sidewalls of circular caverns and ultimately form a symmetrical V-shaped notch. Su et al. [8] found that, after the ejection failure of coarse-grained granite samples, V-shaped or stepped rockburst pits were formed. Zhao et al. [9] carried out biaxial compression tests on sandstone samples with trapezoidal opening. It was found that the failure zones on both sides of the trapezoidal opening were $\mathrm{V}$-shaped under different lateral compressive stress regimes. Wang and Pan [10] used FLAC to simulate the rockburst process of circular tunnel under different lateral pressure coefficients and found that the lateral pressure coefficient affected the shape of rockburst pits. In experimental simulation research, the consensus is that $\mathrm{V}$-shaped rockburst pits will be formed, and the types of rockburst pits in engineering site are more complex than those seen under laboratory conditions.

To reveal the formation process of rockburst, much attention should be paid to the gradual formation process of rockburst pits $[11,12]$. The above research only used numerical simulation and other methods to describe the formation process of rockburst pits (especially V-shaped pits). As Wang et al. point out, the formation of $\mathrm{V}$-shaped pits was only described by the distribution and evolution of plastic zone and shear strain increment in the past literature, and these studies were not detailed enough [13]. The detailed formation process of typical rockburst pits, such as $\mathrm{V}$-shaped and pan-shaped ones, found in experiments or on engineering sites is not yet clear. In particular, the differences and connections between different types of the rockburst pit formation process have not been reported in the literature. As an effective method of studying the failure mechanism of rock, CT allows direct observation of its internal structure, and it has been widely used in rock mechanics research $[14,15]$. On the one hand, CT technology can accurately obtain the three-dimensional structure of the sample after rockburst to determine the shape of rockburst pits accurately, which compensates for the lack of analysis of the shape of rockburst pits by observation. On the other hand, the internal failure characteristics (crack morphology, distribution, etc.) of samples after rockburst are further determined through the detection of the deeper structure of surrounding rock where a rockburst occurs by $\mathrm{CT}$, and the interaction between the internal cracks of surrounding rock and the formation process of rockburst is revealed at a deeper level.

In this paper, a tunnel rockburst simulation test was conducted on granite samples with a circular hole. CT technology was used to scan the samples to analyse the failure characteristics of the tunnel wall after rockburst. Combined with the characteristics of cracks around the tunnel wall, the formation process of different types of rockburst pits was studied. From the point of view of the formation of rockburst pit, the evolution and the breeding mechanism of rockbursts were revealed.

\section{Experimental Method}

Theoretically, the failure mechanism of rockburst is closely related to the high stress state in deep unexcavated rocks, unloading effect of excavation, and external stress disturbance after excavation [16]. In this paper, the design concept of "loading first, tunnel forming, and then loading" was adopted to simulate a rockburst disaster induced by stress adjustment after excavation unloading under a certain stress environment. This experimental method realises the unloading effect after loading, to solve the problem of no excavation unloading effect in the stress path of "opening a hole first and loading later." More importantly, this experimental method can simulate the stress transformation after excavation, which is more consistent with the stress path of rockburst in engineering. The concrete strategy of "loading first, tunnel forming, and then loading" is mainly reflected in two aspects: one is to open a hole after loading to simulate the unloading effect of excavation under certain stress conditions; the other is to simulate the stress adjustment process after excavation by continuous loading. Firstly, similar materials were in-filled within granite samples with circular holes by "opening and filling" method, and then the rockburst simulation test samples were made after curing for three days. Similar materials could expand to ensure the effective cementation of granite and similar materials. Secondly, biaxial loading was conducted on samples. Under certain stress conditions, the similar materials filled in the circular hole were removed by manual excavation to realise the unloading effect in the process of tunnel excavation. Thirdly, after the excavation was completed, loading was continued to simulate the process of stress adjustment, and a rockburst disaster was induced therein.

2.1. Description of Rock Specimens. To simulate the process of excavation after loading, samples were made by "opening + filling." As shown in Figure 1, the granite from Laizhou, Shandong Province, is processed into cuboidal $(150 \times 150 \times 150 \mathrm{~mm})$ samples with a circular hole $(\Phi$ $45 \mathrm{~mm}$ ). The hole was filled with similar materials, and the specific parameters of similar materials are given in previous studies [17]. To ensure the cementation between similar materials and granite, special expansive cement is selected to make the similar material. The similar materials prepared using expansive cement expanded to bind with the granite. The special expansive cement and quartz sand were mixed in the ratio of $1: 1$, and then other materials were added, including water $11 \%$, water reducing agent $0.27 \%$, boric acid $0.2 \%$, and lithium carbonate $0.02 \%$. According to this composition and proportion, the similar materials were made. The similar materials were filled into the circular hole in each granite sample and cured for three days to make rockburst simulation test samples.

2.2. Testing Equipment. The testing equipment is shown in Figure 2: the test system includes a loading device and observation system. The loading device is a RLW-3000 


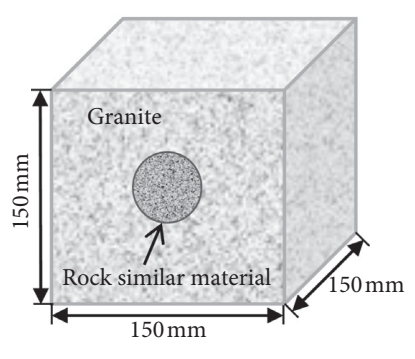

(a)

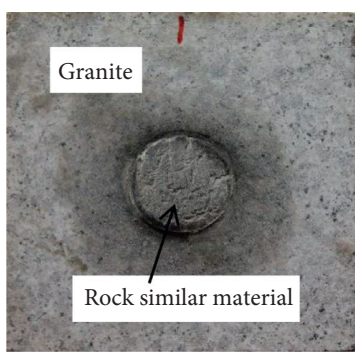

(b)

Figure 1: Experimental specimen.

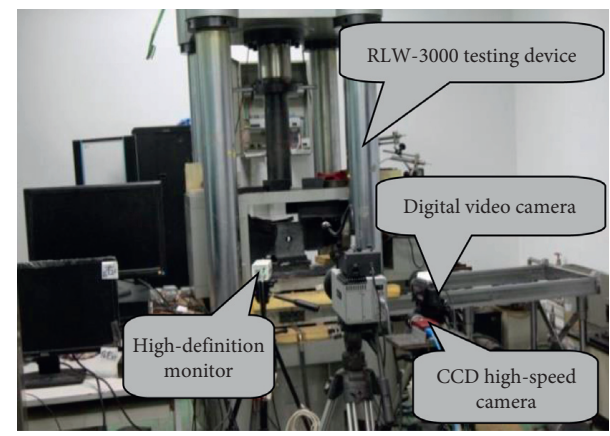

Figure 2: Testing equipment.

servo-controlled test machine. The observation system, composed of CCD high-speed camera, high-definition video monitor, and digital video camera, can record the rockbursts.

2.3. Experimental Scheme. In this paper, the experiment simulates a rockburst that is induced during the stress adjustment process after tunnel excavation unloading under biaxial stress condition. During the experiment, $\sigma_{v}$ and $\sigma_{h}$ were applied by loading in the vertical direction $\left(F_{v}\right)$ and horizontal direction $\left(F_{h}\right)$. The loading path can be divided into the following three stages (Figure 3):

(1) Initial stress field is formed by loading: according to the buried depth and ground stress condition of rockburst projects recorded in previous studies, the initial stress value of the experiment was designed [17]. The vertical load $F_{v}$ and horizontal load $F_{h}$ were (at $800 \mathrm{kN}$ ) $\sigma_{v 0}=35.55 \mathrm{MPa}$ and (at $200 \mathrm{kN}$ ) $\sigma_{h 0}=8.88 \mathrm{MPa}$, respectively, at the same loading rate.

(2) Tunnel excavation: after the initial stress field was formed, it was maintained for 5 mins. The embedded filling materials of the sample were taken out to form the tunnel by means of artificial excavation. After excavation, the load was maintained for $5 \mathrm{~min}$ to achieve the unloading effect during excavation.

(3) Second loading to rockburst: case studies show that most of the strain rockbursts occur in the process of stress adjustment after tunnel excavation and unloading and have the characteristics of time-space lag. Currently, it has been a long time from the dynamic unloading process such as mechanical or blasting excavation, and the surrounding rock of the tunnel is in a quasi-static stress field. It is considered that the occurrence of rockburst is mainly due to the stress adjustment and loading of surrounding rock on both sides when the tunnel faces forward. Referring to the stress path of rockburst simulation experiments in previous studies $[7,9]$, the stress adjustment process after tunnel excavation was simulated by continuous loading, and a strain rockburst was induced. The vertical load $F_{v}$ was applied at a rate of $0.3 \mathrm{~mm} / \mathrm{min}$ and the horizontal load $F_{h}$ remained unchanged.

After the test, the samples with rockburst failure were scanned by CT. The $300 \mathrm{kV} / 500 \mathrm{~W}$ X-ray micro-focus CT system produced by GE company in Germany was used for CT scanning tests (Figure 4). The CT equipment is the first compact $300 \mathrm{kV}$ micro-focus industrial CT system in the world, with a resolution of less than $1 \mu \mathrm{m}$, and can image samples with a maximum diameter of $600 \mathrm{~mm}$ and a height of $600 \mathrm{~mm}$, thus providing the conditions necessary for obtaining the shape of rockburst pits and studying the formation process of rockburst pits.

\section{Observations of Rockbursts}

The rockburst process was analysed by Liang et al. [17], as well as previous studies on similar physical models of rock in compression [18-20], concluding on the observation of rockburst process (Figure 5). There are four typical stages of tunnel rockburst, including a quiet period, particle ejection, spalling with particle ejection, and burst jetting. When a rockburst occurs in the test, many cuttings and particles are ejected at a certain speed, accompanied by clear crackling sound. Figure 6 shows a rockburst disaster in the Bayu Tunnel of the Sichuan-Tibet Railway: debris fog ejection occurred in the test akin to the characteristics of the rockburst in the project field. The dynamic failure phenomenon of a rockburst was well simulated by the test.

The observation angle may affect understanding of the shape of a rockburst pit: to observe the shape of a rockburst pit directly from different angles, the sample was divided into two parts along the vertical diameter of the circular hole after CT testing. According to observations from different 


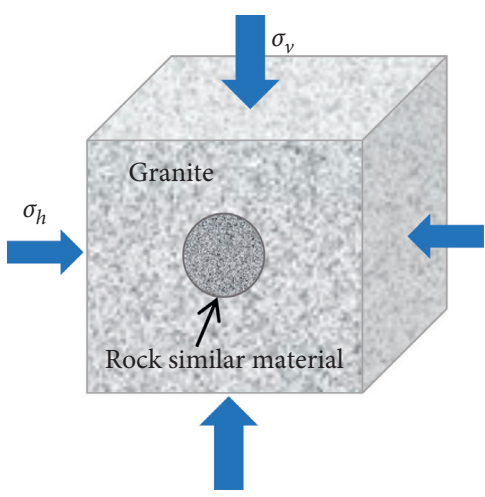

(a)

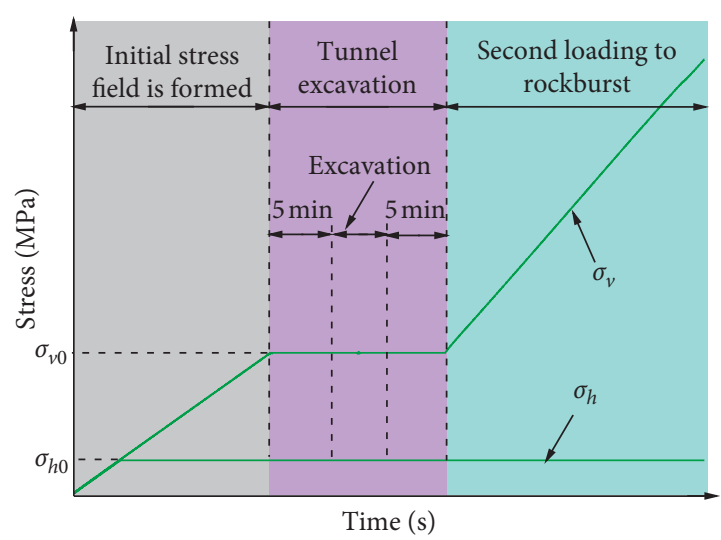

(b)

FIGURE 3: Experimental specimen.



FIGURE 4: Industrial CT system.



(a)



(b)

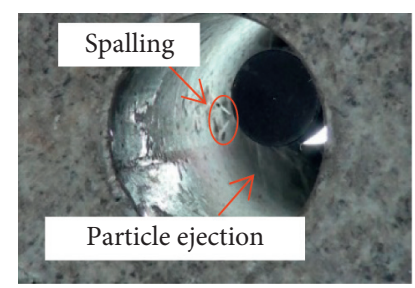

(c)

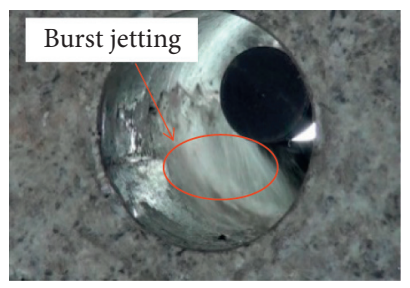

(d)

FIgURE 5: Typical failure characteristics of rockburst process [17]. (a) Quiet period. (b) Particle ejection. (c) Spalling with particle ejection. (d) Burst jetting.

angles, the failure characteristics of circular hole wall after rockburst are shown in Figure 7: a rockburst band is formed on both circular hole sidewalls after a rockburst (Figures 7(a) and 7(b)). Rockburst simulation tests of the sample containing a circular hole were conducted by $\mathrm{Hu}$ et al. [18] and Gong et al. [19], and the rockburst bands appear on both circular hole sidewalls (Figure 8). It is consistent with the loading method described in this paper that the simulation tests of rockbursts under biaxial loading were conducted by $\mathrm{Hu}$ et al. (Figure 8(a)). Figure 8(a) shows two V-shaped failure bands, forming a $\mathrm{V}$-shaped notch at each cross- section along the opening axis, and at the two sidewalls with different perspectives. To investigate the occurrence of strain rockbursts in deep circular cavern under high stresses, Gong et al. conducted simulation experiments on cubic granite specimens with a prefabricated circular hole using the truetriaxial electro-hydraulic servo-controlled testing system. Eventually, two V-shaped notches were formed on both circular hole sidewalls (Figure 8(b)), akin to that obtained in the test (Figures 7 and 8(a)). From the point of view of the failure characteristics of the tunnel wall after rockburst, whether under biaxial stress conditions or true triaxial stress 



Figure 6: A rockburst in the Bayu Tunnel of Sichuan-Tibet Railway.



(a)

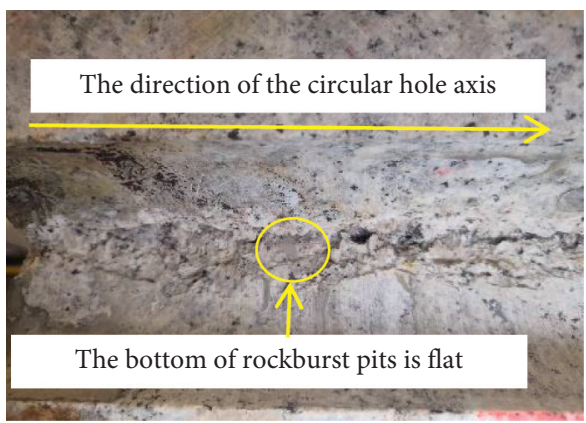

(c)

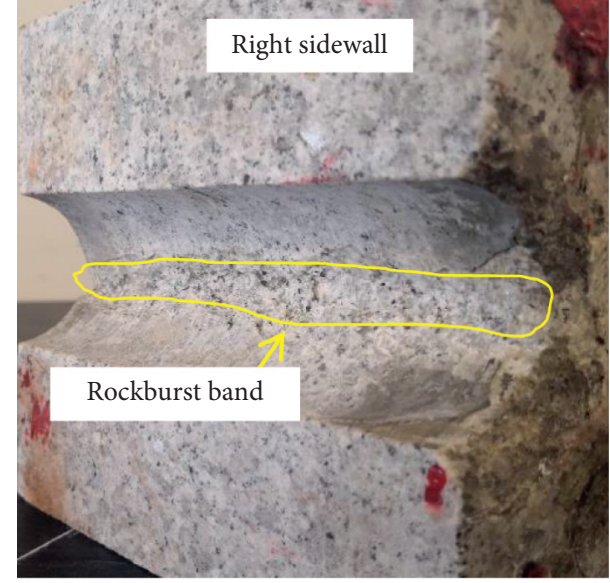

(b)

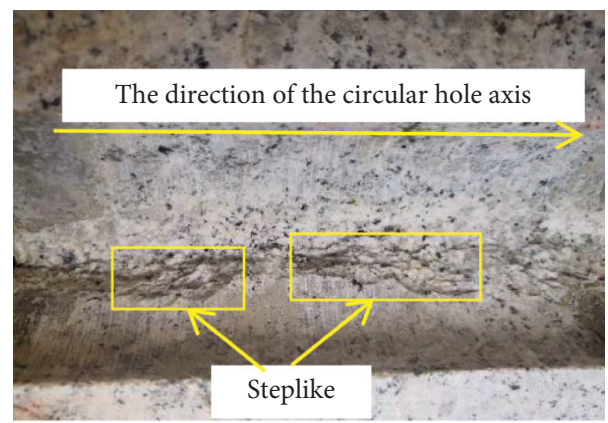

(d)

FIgURE 7: Failure characteristics of circular hole wall after rockburst.

conditions, the failure characteristics of tunnel wall after rockburst have a certain similarity.

The rockburst pit shape is simply observed from the hole opening, and it is considered that the rockburst band is V-shaped. A local rockburst occurs at a certain position on the circular hole wall, followed by local rockbursts at multiple positions, and then the overall rockburst occurs, forming a rockburst band [18]. In the case of rockburst on project site, rockburst bands also appear [21]. Combined with Figures 7(c) and 7(d), the shape and range of rockburst pits are different due to the different positions on the circular hole wall. In terms of shape, the bottom of the rockburst pit is relatively flat in some locations (Figure $7(\mathrm{c})$ ), and the rockburst pit is steplike in other locations (Figure 7(d)). In terms of scope, the specific size of the rockburst pit is different. The difference is related to the formation process, scale, and intensity of a local rockburst. From the above analysis, the rockburst band is formed on the left and right wall of the circular hole wall, which is consistent with the existing research, but further understanding suggests that the shape of the rockburst pit is different at different positions on the rockburst band.

\section{Analysis of Rockburst Pit Shape Based on CT}

CT technology allows us to understand the shape of rockburst pits, and a series of CT images of the sample after rockburst along the axis of the hole can be obtained (Figure 9). As shown in Figure 9(b), the depth of rockburst pits is defined as the horizontal distance from the hole wall to the 


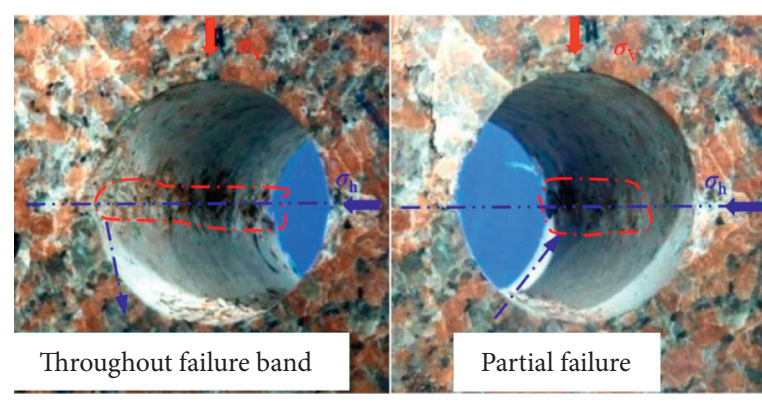

(a)

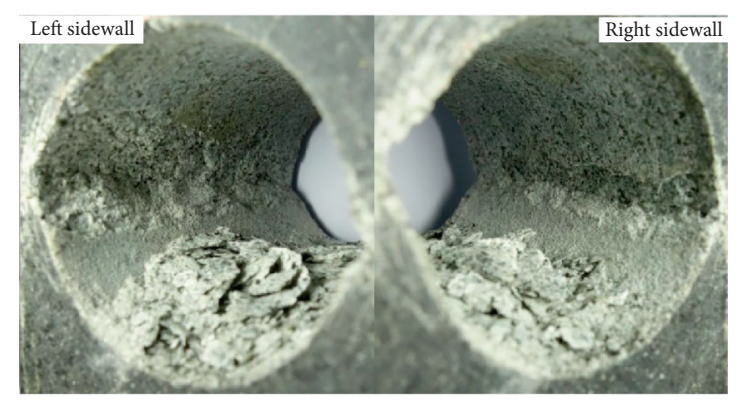

(b)

FIGURE 8: Rockburst bands on both circular hole sidewalls. (a) V-shaped failure bands after rockburst [18]. (b) V-shaped notches on both circular hole sidewalls [19].

bottom of rockburst pits, denoted by $D$; the width of rockburst pits is the vertical damage range of the hole wall, denoted by $L$.

Figure 10 shows a series of CT images of a sample after rockburst along the axis of the hole. According to the CT images, the appearance contour characteristics of rockburst pits can be obtained. Figure 10(a) shows that V-shaped rockburst pits are formed on both circular hole sidewalls, Figure 10(b) demonstrates that pan-shaped rockburst pits are formed on both circular hole sidewalls, and Figures 10(c) and $10(\mathrm{~d})$ show a pan-shaped rockburst pit on the left wall and a $\mathrm{V}$-shaped rockburst pit on the right wall. According to the shape of rockburst pits on CT images, there are two types of rockburst pits: pan-shaped and V-shaped. The bottom of the pan-shaped rockburst pit is flat, and the upper and lower edges are approximately horizontal. The upper and lower edges of the $\mathrm{V}$-shaped rockburst pit are uneven, and the contours are $\mathrm{V}$-shaped. Combined with CT images, it is found that there are differences in the shape of rockburst pits at different positions along the axis of the circular hole. From the view of single side wall, there are two types of rockburst pits, i.e., pan-shaped and V-shaped, in different positions of the circular hole wall; from the perspective of both sides, the two types of rockburst pits may appear either symmetrically or asymmetrically. Due to the influences of sample anisotropy, machining accuracy, and control accuracy of loading equipment, absolute symmetry is difficult to realise. The asymmetry of rockburst pits on both circular hole sidewalls exists objectively, and this phenomenon also appears in the test results of He et al. [22] and Gong et al. [23].

It can be seen that $\mathrm{V}$-shaped rockburst pits are often formed on both circular hole sidewalls through direct visual observation [18-20]: however, the accurate shape of rockburst pits on the circular hole sidewall can be obtained by CT technology, and it is found that there are two types of rockburst pits: pan-shaped and V-shaped. Combined with the CT images shown in Figure 10, it is found that there is a main crack parallel to the main stress $\sigma_{v}$ at the bottom of the pan-shaped rockburst pits; on the contrary, there is no main crack parallel to the main stress $\sigma_{v}$ around the $\mathrm{V}$-shaped rockburst pits. This means that the formation of two types of rockburst pits (pan-shaped and V-shaped) is closely related to the cracks on the sidewall around the circular hole.
Furthermore, to analyse the formation process of rockburst pits, it is necessary to analyse the crack characteristics around the rockburst pits combined with CT images.

\section{Analysis of Crack Characteristics around Rockburst Pits Based on CT}

Figure 11 shows the cracks parallel to $\sigma_{v}$ around the rockburst pits: there are many cracks parallel to the main stress $\sigma_{v}$ in the rock near the circular hole sidewall. As shown in Fig 11(c) and 11(d), to distinguish these cracks parallel to the main stress $\sigma_{v}$, the cracks are labelled $1,2,3,4$, etc. These cracks appear at a certain distance from the sidewall of the circular hole and cannot be seen directly inside the hole, especially in underground engineering operations. The presence of these cracks has been proved by physical model tests by Gay [24] and Lotidis et al. [25]. Hoek [26] analysed the origin of these cracks using photo-elastic coating techniques and concluded that there is a concentration of tensile stress on the left and right sides of the circular hole, which may become large enough to propagate in a stable manner and lead to tensile fracture. Based on Hoek's results, Ingraffea [27] further confirmed that tension is generated in more remote regions, causing fracturing. The mechanism of these cracks is that tensile stress is produced at the left and right sides of the hole under stress $\sigma_{v}$, and tensile microcracks gradually develop, forming a typical tensile failure. In these cracks, there is a main crack running approximately parallel to $\sigma_{v}$, which is relatively long and gradually shifts towards the hole while extending to the upper and lower boundaries of the model. After measurement, the distance (d) from the main crack to the hole centre is about 1.1 times the hole radius, which determines the depth $(D)$ of rockburst pits to a certain extent. For a pan-shaped rockburst pit, the depth $D_{1}$ is less than or equal to $d$, while for a V-shaped rockburst pit, it readily develops into the surrounding rock, and its depth $D_{2}$ is greater than $d$.

When Carter et al. [28] analysed the fracture characteristics around a circular hole, they defined the multiple tensile cracks that formed on the left and right sides of the circular hole as remote fractures (RF), and considered that the remote fractures form on the left and right sides of the hole and expand in a direction parallel to the principal stress. 


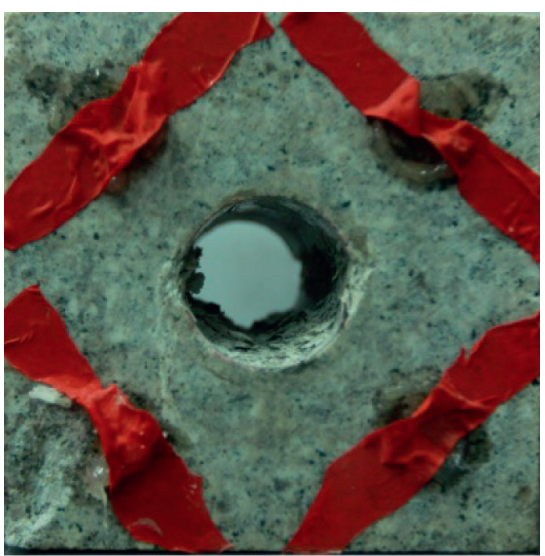

(a)

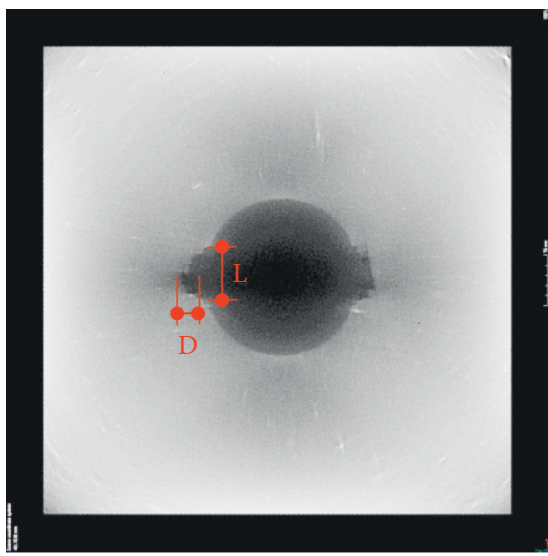

(b)

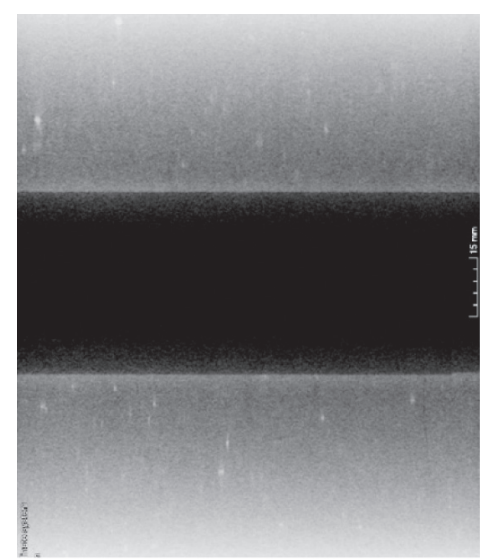

(c)

FIgure 9: Correspondence between the original sample and CT image. (a) Original sample. (b) CT elevation view. (c) CT left view.

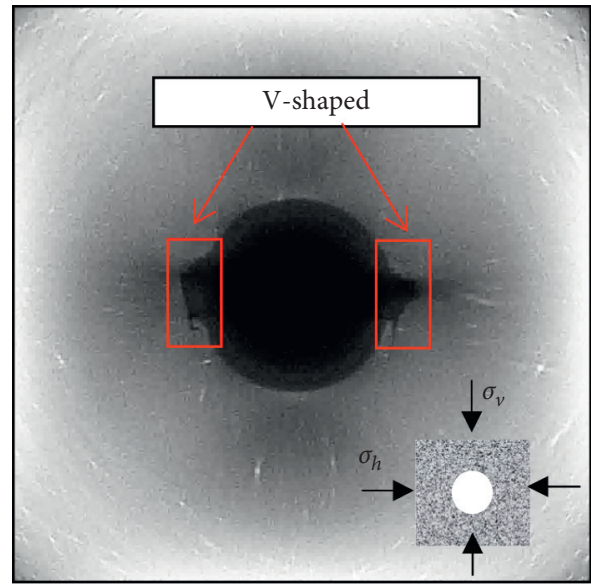

(a)

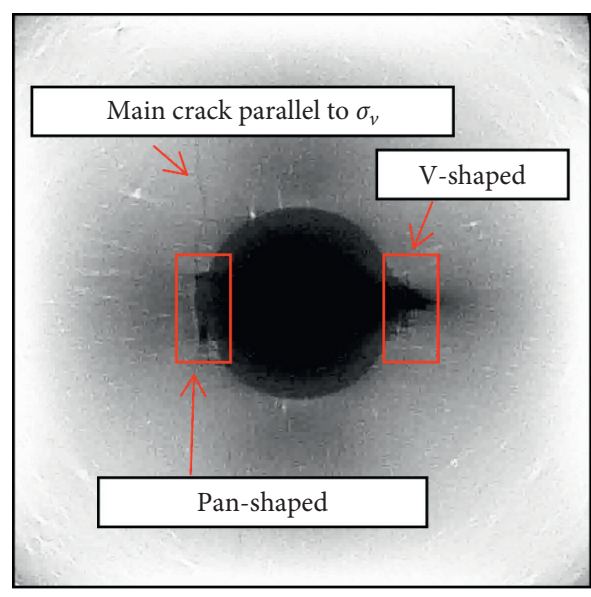

(c)

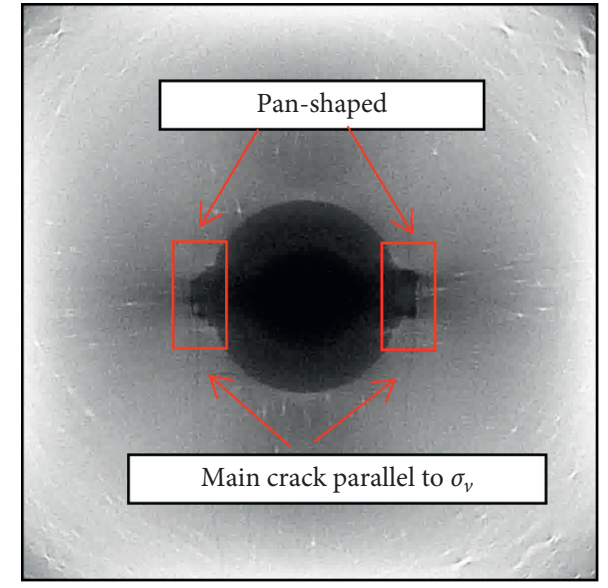

(b)

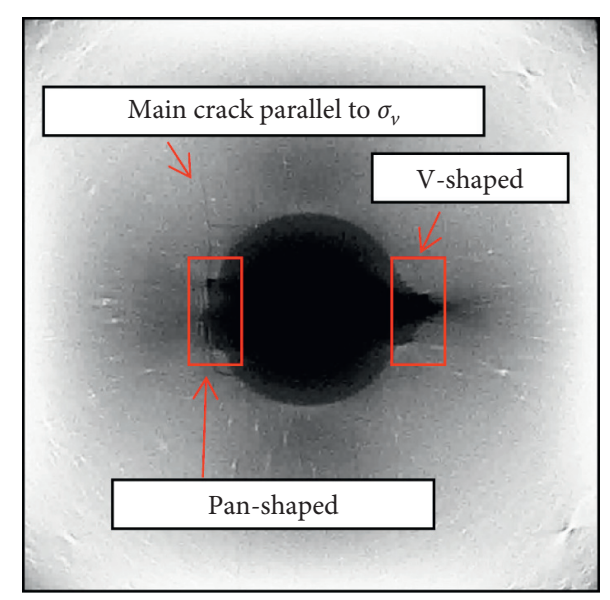

(d)

FIgURE 10: A series of CT images along the axis of the circular hole.

An important feature of remote fractures is that they are not a single crack, but a fracture zone composed of a series of parallel cracks (Figure 12(a)). The location of the main crack is affected by the hole diameter and confining pressure
$[28,29]$. This shows that the occurrence of rockburst is closely related to the remote fracture on the left and right sides of the hole. The remote fracture starts from the left and right sides of the hole and will gradually develop to the upper 




(a)

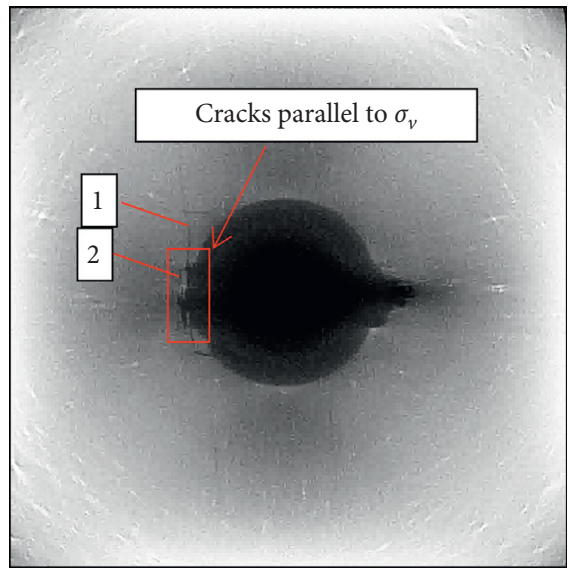

(c)

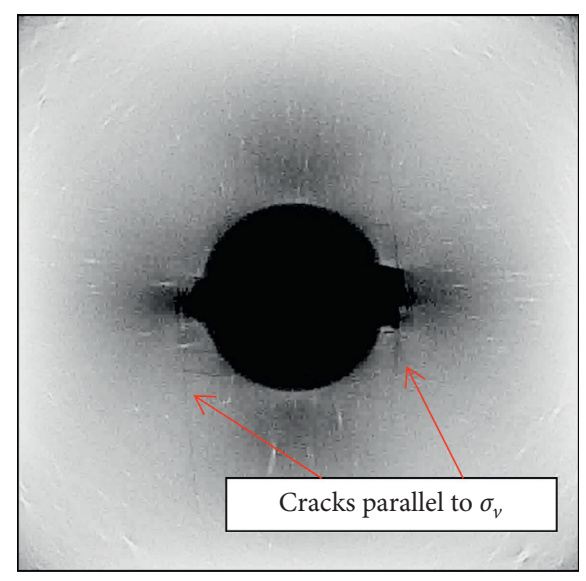

(b)

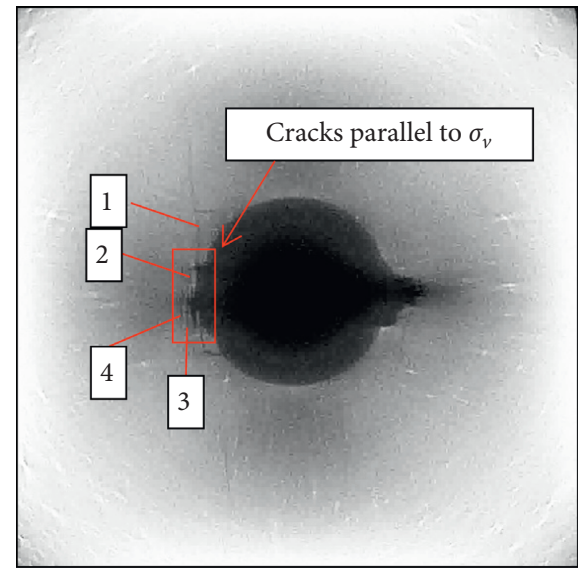

(d)

FIGURE 11: Cracks parallel to $\sigma_{v}$.

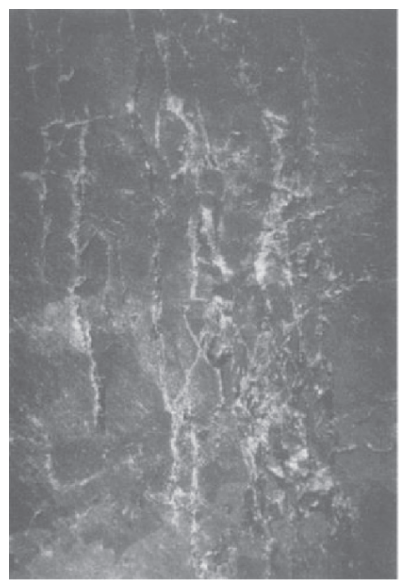

(a)

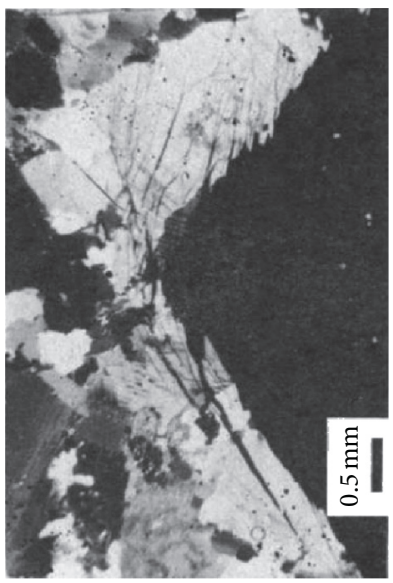

(b)

FiguRE 12: Remote fractures around the circular hole. (a) Remote fracture zone in the anorthosite block [28]. (b) Spalling in V-shaped failure [6]. 
and lower boundaries of the model and the circular hole sidewall. There are many cracks parallel to the principal stress $\sigma_{v}$ in the left and right sidewalls of the circular hole, resulting in slabbing failure of surrounding rock.

Figures 13(a) and 13(b) show cracks perpendicular to $\sigma_{v}$ are formed on both sides of the hole. Figure 13(c) presents there are three cracks (labelled 1,2, and 3) perpendicular to the principal stress $\sigma_{v}$ in the left sidewall of the hole. This is also confirmed in Figure 13(d): there are many cracks perpendicular to the principal stress $\sigma_{v}$ in the left sidewall of the hole. The length of these cracks is relatively short, and their range of propagation does not exceed the diameter of the hole (Figures 13(a)-13(c)). In most cases, these cracks propagate horizontally from the wall to the interior of the rock and gradually intersect the cracks formed on the left and right sides of the hole which are approximately parallel to $\sigma_{v}$. Compared with the cracks parallel to $\sigma_{v}$, most of the cracks perpendicular to $\sigma_{v}$ intersect the wall of the cavity, which may be found inside the cavity, and the concealment thereof is relatively weak. Compared with cracks parallel to $\sigma_{v}$, the cracks perpendicular to $\sigma_{v}$ tend to intersect the circular hole sidewall and may be found in the hole. From a single side wall, two main cracks perpendicular to $\sigma_{v}$ appear near the top and bottom of the hole. The distance between the two cracks is about 0.75 times the tunnel radius and to a certain extent determines the width $(L)$ of rockburst pits.

Carter et al. [28] found a horizontal crack at the upper left corner of the hole when analysing the characteristics of cracks around the circular hole, which was considered interesting, but did not conduct a detailed analysis (Figure 14). Wang and Pan $[10,13]$ also found a similar phenomenon in the numerical simulation analysis of this kind of crack. During the numerical simulation of a circular tunnel, a series of shear bands appeared, and these shear bands were only under the top or above the bottom of the tunnel, and the shear bands were not observed within a range exceeding the tunnel diameter.

According to the outline of rockburst pits, the upper and lower edges of rockburst pits are approximately horizontal, and there are several horizontal steps (Figure 13(d)): these are related to the cracks perpendicular to the stress $\sigma_{v}$. In a rockburst, several cracks perpendicular to the principal stress $\sigma_{v}$ will be formed in the stress concentration area around the hole, and these cracks interact with those formed parallel to the principal stress $\sigma_{v}$, resulting in a rockburst disaster.

Through the analysis of the crack characteristics around the circular hole, it is found that there are two types of cracks: those parallel to, and perpendicular to, the principal stress direction. Under the interaction of two types of cracks parallel to and perpendicular to the principal stress direction, rocks on the left and right sides of the circular hole are cut into rock blocks, and the rock mass is ejected to form a rockburst pit.

\section{Formation of Rockburst Pits}

6.1. Pan-Shaped Rockburst Pits. Figure 15 shows the formation pan-shaped rockburst pits. Under principal stress $\sigma_{v}$, many tensile microcracks are initiated and develop
(Figure 15(a)), and the crack propagation direction is approximately parallel to $\sigma_{v}$, resulting in remote fractures on the left and right sides of the hole. Figure 15(a) shows some tensile microcracks on the left and right sides of the hole. In fact, there are many microcracks, which are much denser than those shown in Figure 15(a). Under the continuous action of the principal stress $\sigma_{v}$, tensile microcracks develop towards the upper and lower boundaries of the model and the left and right sidewalls of the hole. The tensile microcracks close to the sidewall of the hole interconnect and gradually form a main crack parallel to $\sigma_{v}$ near the sidewall (Figure 15(b)). At this point, many cracks perpendicular to the $\sigma_{\nu}$ direction are generated and spread on both sides of the hole, interacting with the main crack formed parallel to $\sigma_{v}$ (Figure 15(c)). These two types of cracks intersect on the left and right sides of the hole, cutting the wall rock into blocks, finally forming a rockburst pit after rock blocks are ejected (Figures 15(d) and 15(e)).

6.2. V-Shaped Rockburst Pits. Figure 16 shows the CT images of pan-shaped and V-shaped rockburst pits. From the outline of rockburst pits, the upper and lower edges of a V-shaped rockburst pit appeared steplike, and each step forms a rockburst pit similar to the pan-shaped pit. Therefore, a V-shaped rockburst pit is further evolved from pan-shaped rockburst pits. Based on the first pan-shaped rockburst pit on the sidewall of the hole, the second gradually forms, and finally several pan-shaped rockburst pits are formed. There are many rockbursts in the forming process of a V-shaped rockburst pit, and finally it is composed of several pan-shaped rockburst pits. Based on this, combined with the previous analysis, the detailed formation process of $\mathrm{V}$-shaped rockburst pits is proposed.

The initial formation of V-shaped rockburst pits is like that of pan-shaped rockburst pits. Under the principal stress $\sigma_{v}$, a large number of tensile microcracks initiate and develop (Figure 17(a)), and the crack propagation direction is approximately parallel to $\sigma_{v}$, resulting in remote fractures forming on the left and right sides of the hole. The difference is that the microcracks do not interconnect to form a main crack parallel to $\sigma_{v}$. Instead, they are layered along the left and right sides of the wall. Under the continuous action of the principal stress $\sigma_{v}$, cracks perpendicular to $\sigma_{v}$ begin to gradually develop on the left and right sides of the hole wall. These cracks expand in the horizontal direction and may induce interpenetration of tensile microcracks surrounding the wall [30]. The interaction of two types of cracks causes the rock nearest to the sidewall to be cut into blocks (Figure 17(b)), and the rock blocks are ejected, resulting in a rockburst disaster and forming the first pan-shaped rockburst pit (Figure 17(c)). After, or during the formation of the first pan-shaped rockburst pit, the cracks perpendicular to $\sigma_{v}$ continue to develop into the interior of the rock along the horizontal direction, inducing the tensile microcracks to connect and interact with the tensile microcracks (Figure 17(d)). The rock is cut into blocks again, and the rock blocks are ejected, resulting in a rockburst disaster, forming the second pan-shaped rockburst pit (Figure 17(e)). 


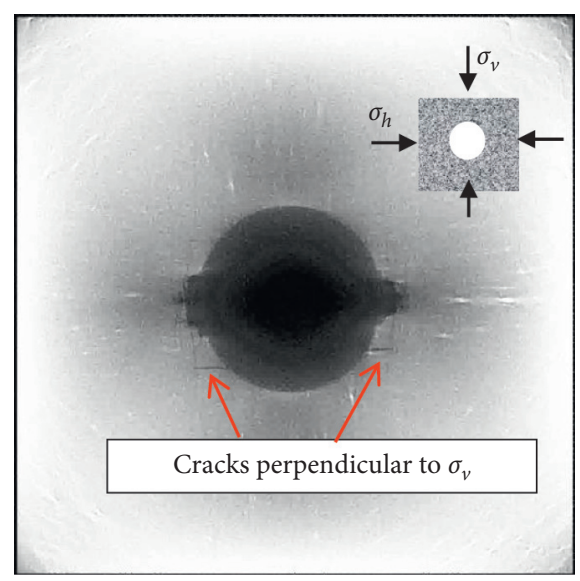

(a)



(c)

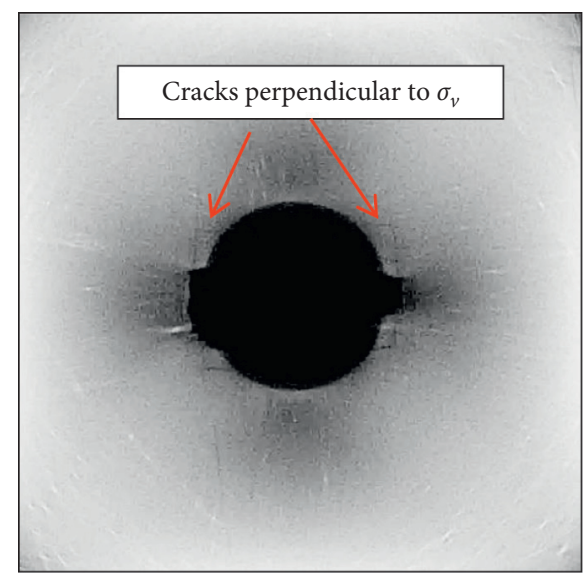

(b)

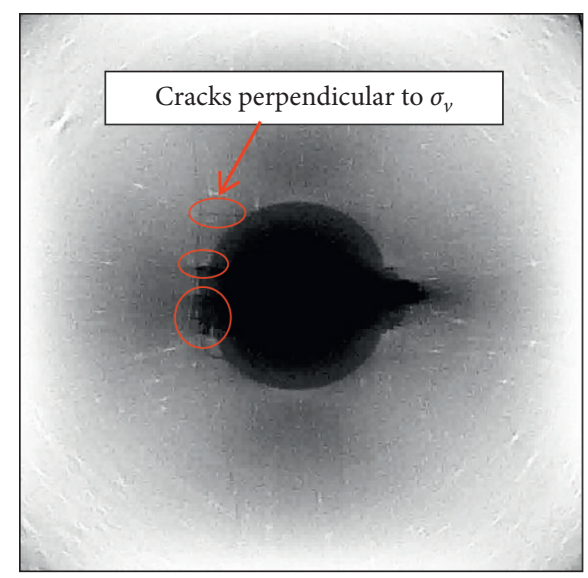

(d)

FIGURE 13: Cracks perpendicular to $\sigma_{v}$.

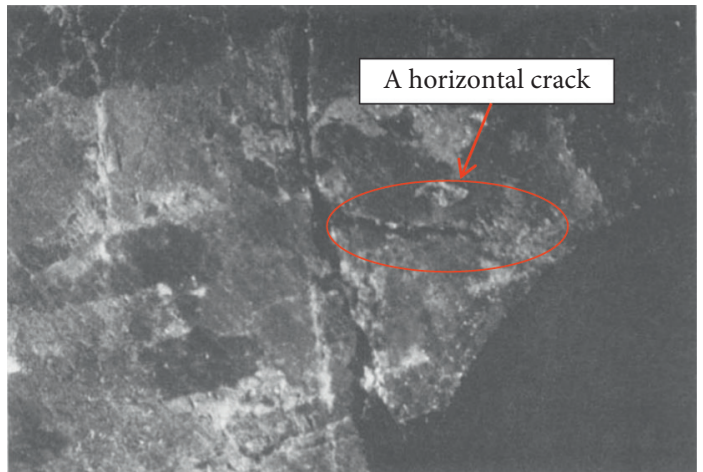

FIGURE 14: The appearance of an unexplainable "horizontal fracture" in the anorthosite block [28].

Thereafter, the process shown in Figure 17(d) is repeated, and the cracks perpendicular to $\sigma_{v}$ continue to develop and interact with the tensile microcracks distributed throughout the rock, finally forming a V-shaped rockburst pit (Figure 17(f)).

\section{Discussion}

7.1. Failure Range of Rockbursts in a Circular Tunnel. Based on the analysis of cracks around rockburst pits based on CT, it is found that two types of cracks parallel to and 


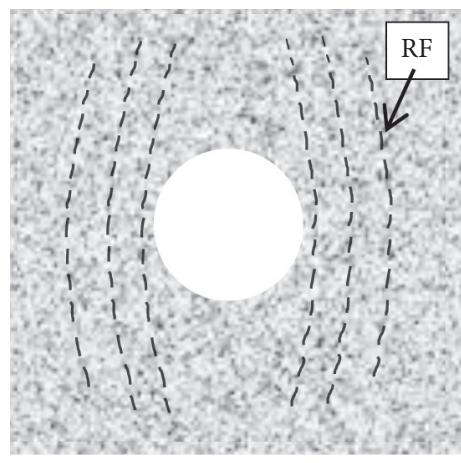

(a)

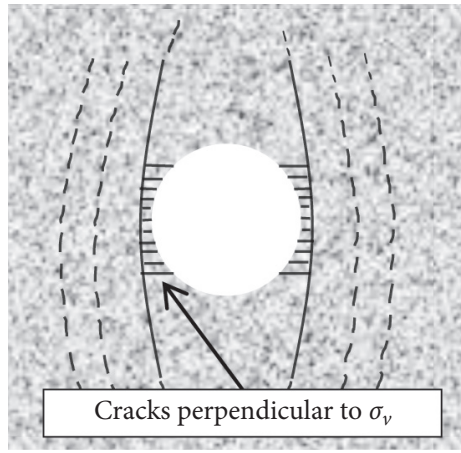

(c)

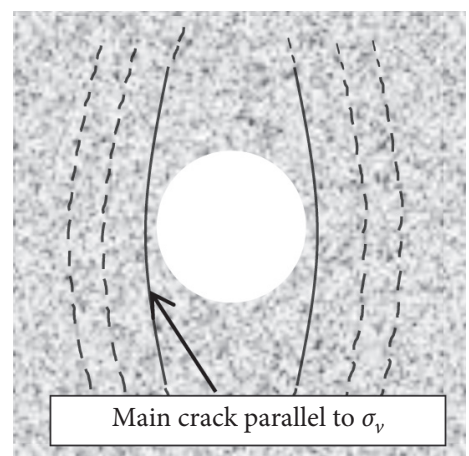

(b)

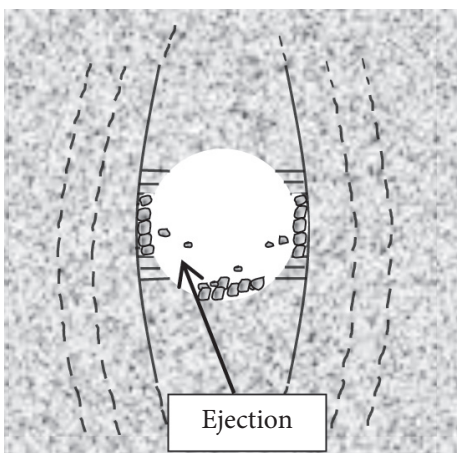

(d)

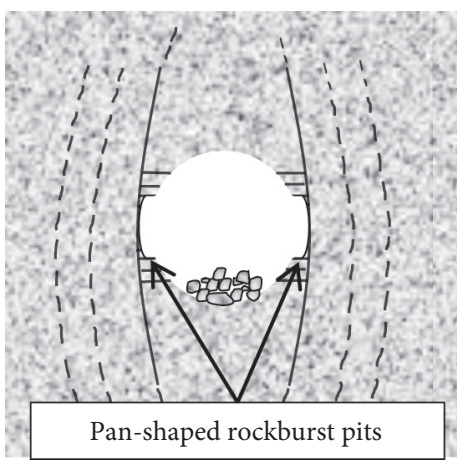

(e)

FIGURE 15: Schematic illustration of pan-shaped rockburst pits formation process.

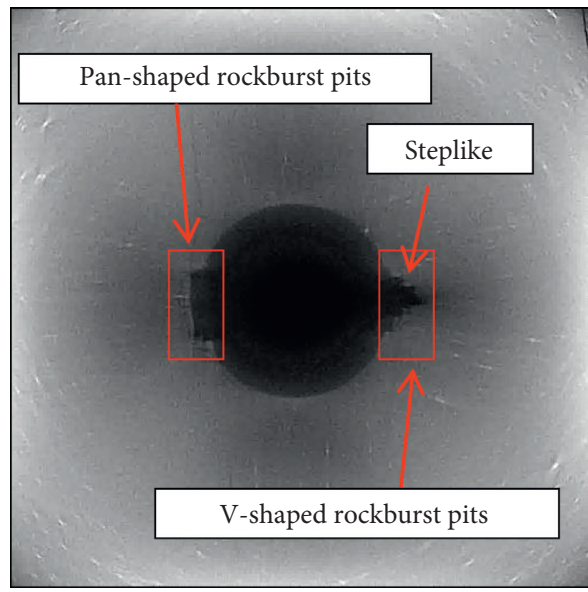

(a)

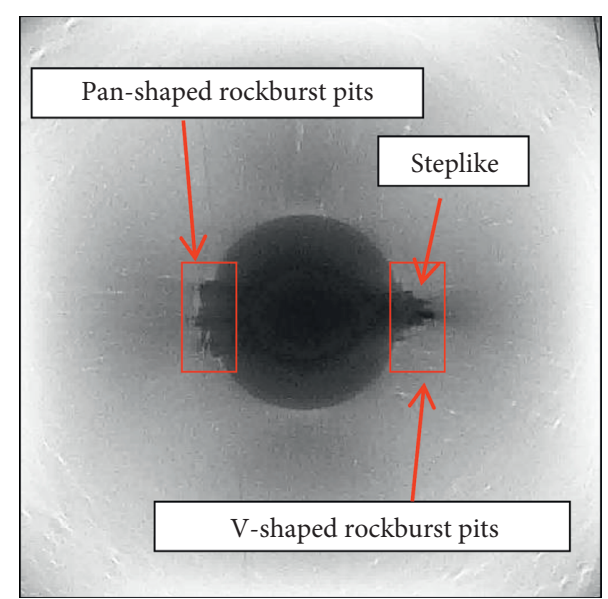

(b)

Figure 16: CT images of V-shaped and pan-shaped rockburst pits. 


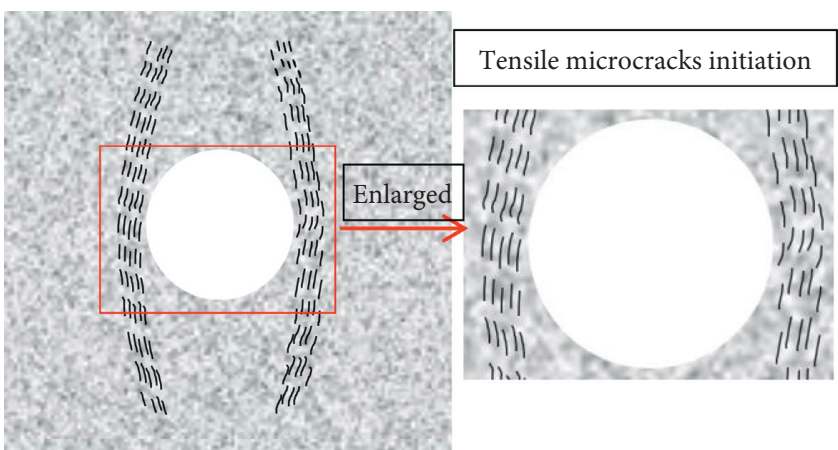

(a)



(c)

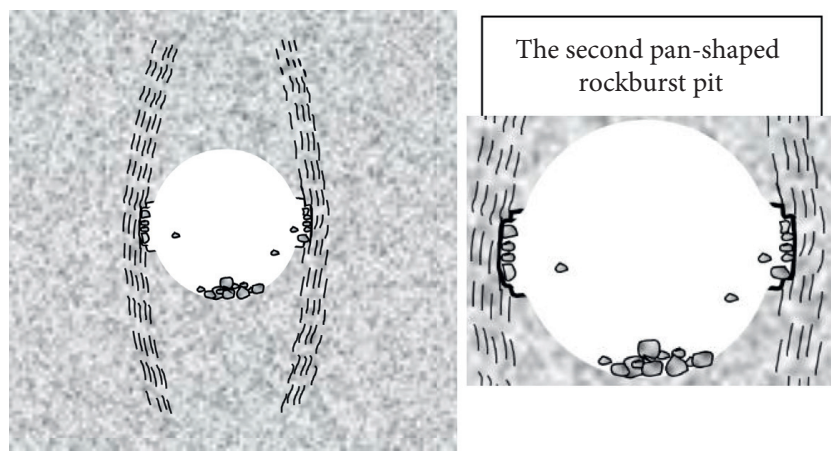

(e)

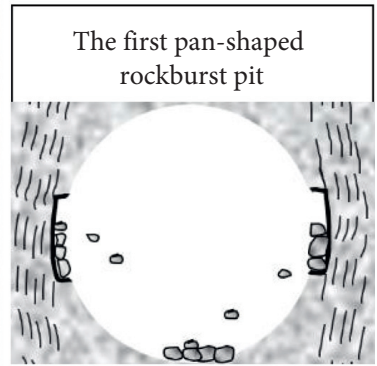

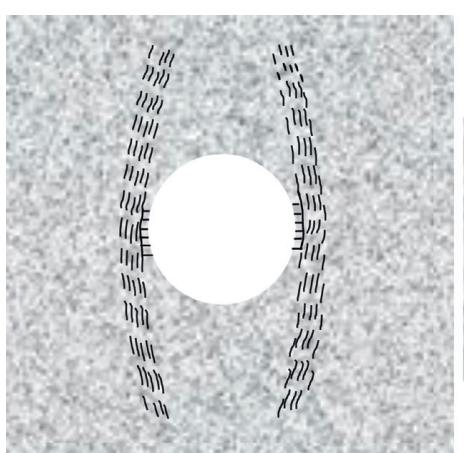

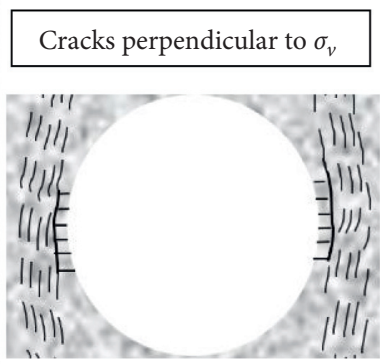

(b)


(d)



(f)

FIGURE 17: Schematic illustration of V-shaped rockburst pits formation process. (a) Tensile microcracks initiation. (b) Cracks perpendicular to $\sigma_{v}$. (c) The first pan-shaped rockburst pit continue to grow. (d) Cracks perpendicular to $\sigma_{v}$. (e) The second pan-shaped rockburst pit. (f) $\mathrm{V}$-shaped rockburst pits.

perpendicular to $\sigma_{v}$ are generated on the left and right walls of the circular hole during the rock burst. From the single side wall, the cracks parallel to $\sigma_{v}$ form a main crack near the wall, and the cracks perpendicular to $\sigma_{v}$ form two main cracks near the top and bottom of the circular hole. Two types of main cracks are generated around the wall of the hole, resulting in a crescent-shaped failure area on both sides of the hole, as shown in Figure 18. The rock blocks in the middle of the crescent-shaped failure area are ejected, resulting in a rockburst disaster and forming a rockburst pit. Although the rocks in the upper and lower parts of the rockburst pit have not been ejected, they have been separated from the surrounding rock and become a potential danger. The boundary of the crescent-shaped failure area determines the range of rockburst failure. Specifically, the depth of rockburst pits is determined by the main crack parallel to $\sigma_{v}$, while the width of rockburst pits is determined by the main crack perpendicular to $\sigma_{v}$. The position of two kinds of main cracks can be measured by CT technology. In this paper, the distance between the main crack parallel to $\sigma_{v}$ and the centre of the hole is about 1.1 times the radius of the hole, and the distance between the two main cracks perpendicular to $\sigma_{v}$ is 0.75 times the tunnel radius, which provides a quantitative calculation basis for determining the range of occurrence of rockbursts in the rock surrounding the circular tunnel.

7.2. Influence of Structural Plane on Rockburst. Based on the experimental results, the rockburst pit is formed under the interaction of two types of cracks parallel and perpendicular 



FIGURE 18: Damage areas on left and right sides of circular hole.

to $\sigma_{v}$. The degree of development of cracks parallel to $\sigma_{v}$ affects the type of rockburst pits. If a main crack parallel to the principal stress $\sigma_{v}$ is formed near the circular hole wall, it is easy to form a pan-shaped rockburst pit; on the contrary, a $\mathrm{V}$-shaped rockburst pit will be formed. In the field, the main cracks which are parallel to the principal stress $\sigma_{v}$ near the circular hole wall can be considered as joints, fissures, and other structural planes parallel to the principal stress direction in the surrounding rock of the tunnel. Scholars also defined the rockburst under the influence of structural planes as structure-type rockbursts and strain-structure-type rockbursts $[2,31]$. Combined with this type of rockburst, the influence of structural plane on rockbursts is discussed.

On the one hand, if there are joints, fissures, and other structural planes in the surrounding rock of the tunnel, especially when the structural plane is close to the tunnel, the structural plane becomes the main factor inducing the rockburst, and a structure-type rockburst disaster readily occurs (Figure 19(a)). In this experiment, a main crack which is approximately parallel to the principal stress $\sigma_{v}$ appears in the wall of circular hole, resulting in a pan-shaped rockburst pit. Akin to the experimental phenomenon, Zhou et al. [32] point out that the structural plane normal to the tunnel side wall readily causes the surrounding rock to crack, thus inducing the tension-plate-type rockburst, forming a pan-shaped rockburst pit. Jia and Zhu [33] studied the relationship between the direction of structural plane and the location of rockburst by numerical simulation and considered that joints and other structural planes play a dominant role in the location of rockburst area. On the other hand, as shown in Figure 19(b), there are joints, fissures, and other structural planes in the surrounding rock on the left side of the tunnel, at a certain distance from the tunnel wall. The structural plane may hinder the formation of $\mathrm{V}$-shaped rockburst pits and produce pan-shaped rockburst pits. There is a main crack parallel to the main stress $\sigma_{v}$ on the left side of the circular hole, which causes a rockburst and forms a panshaped explosion pit; if there is no main crack on the left side of the circular hole, multiple rockbursts occur continuously and a V-shaped rockburst pit is gradually formed (Figures 10(c) and 10(d)). Zhang et al. [34] found that the structural plane hindered the adjustment of the stress in the surrounding rock to the deeper rock mass, resulting in stress concentration and energy accumulation of the rock mass between the excavation boundary and the structural plane. This also explains why there is a main crack formed in the wall of the circular hole in the experiment; it does not further develop to greater depth within the rock after the formation of a pan-shaped rockburst pit.

In engineering practice, structural planes with complex types and occurrences are often distributed in the rock surrounding a tunnel (albeit hidden). The surrounding rock with structural planes is prone to rockburst disaster, but the structural planes may also hinder the development of a deeper rockburst, controlling the boundary of the rockburst, and determining the depth of rockburst pits to a certain extent. Therefore, attention should be paid to the important influence of structural planes on rockburst occurrence.

7.3. Relationship between Pan-Shaped and V-Shaped Rockburst Pits. We found that there is a relationship between pan-shaped and V-shaped rockburst pits in their formation process. During the formation of a V-shaped rockburst pit, several rockbursts occur, and each rockburst forms a pan-shaped rockburst pit. In the process of developing from the tunnel wall to greater depth in the rock, the width of the pan-shaped rockburst pit gradually decreases, and a V-shaped rockburst with a stepped upper and lower boundary is formed. Hou et al. [35] point out that, after the shear-type rockburst occurred in the tunnel of Jinping II Hydropower Station, the rockburst pit is funnel-shaped. On this basis, $\mathrm{Ma}$ et al. [30] considered that the shear-type rockburst may be an illusion produced by multiple continuous rockbursts (Figure 20), which is akin to the viewpoint of gradual formation of $\mathrm{V}$-shaped rockburst pits proposed here. $\mathrm{Hu}$ et al. [18] found that several rockbursts may occur continuously at a certain position on the tunnel wall in the experiment; after one rockburst, the surrounding rock has high strain energy, which can provide enough energy for the next rockburst. Therefore, the local rockburst on the tunnel wall may be composed of multiple rockbursts. After the continuous 


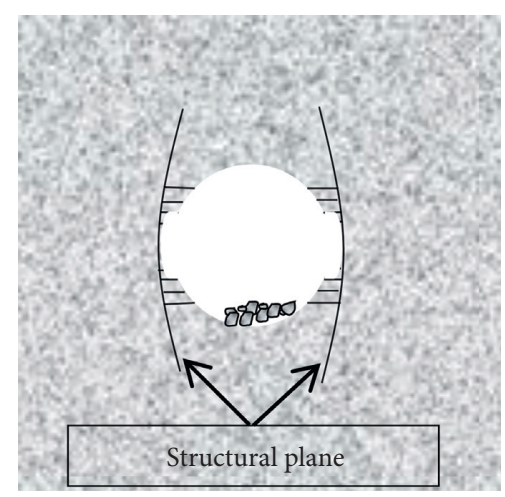

(a)

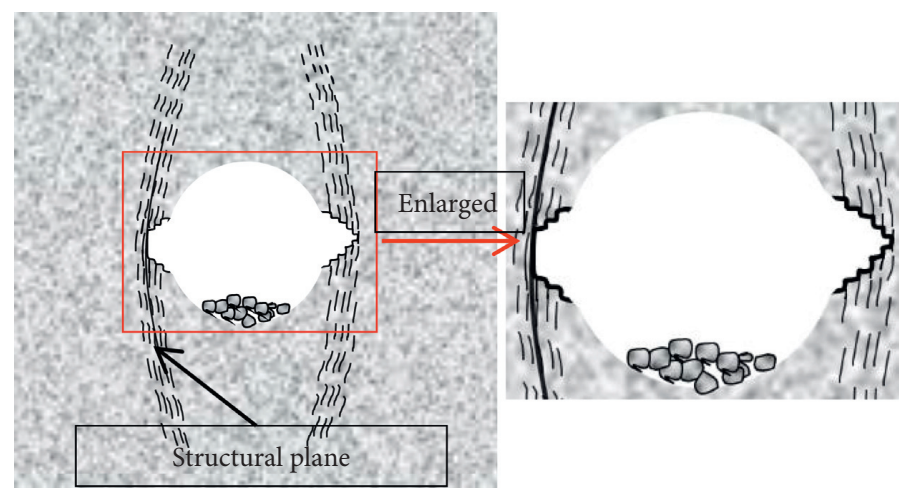

(b)

Figure 19: Influence of structural plane on rockburst.
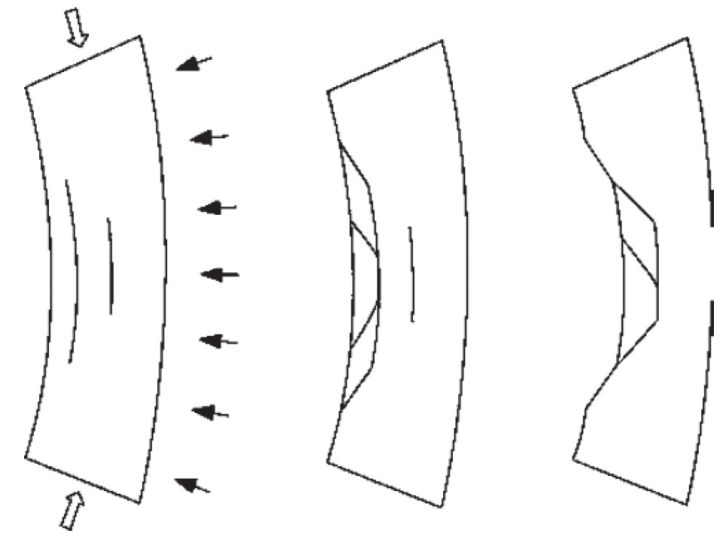

Figure 20: Illusion of several successive rockbursts [30].

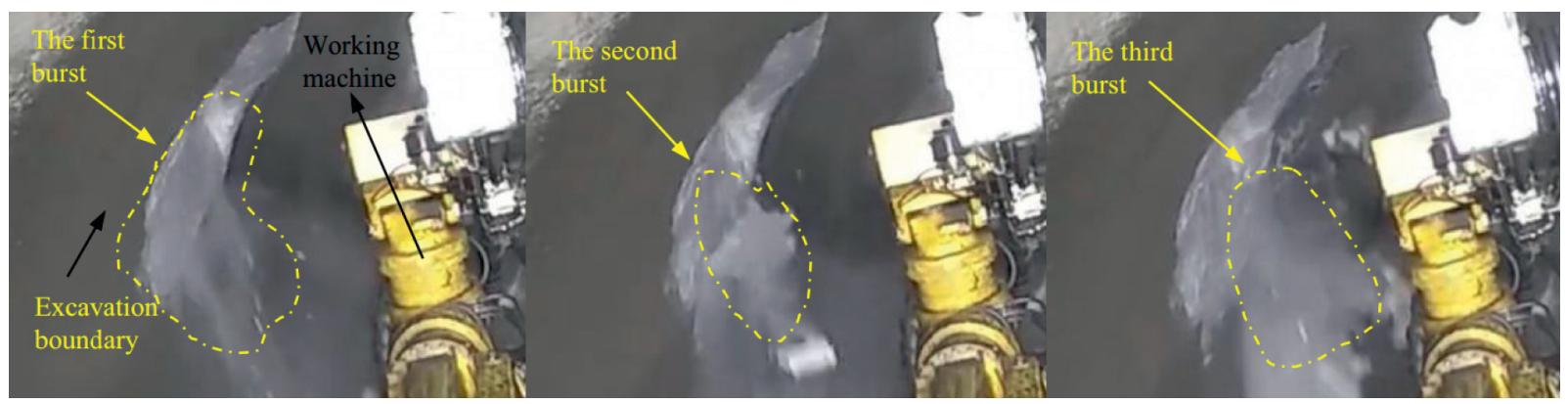

Figure 21: Video capture of in situ rockburst at the tunnel of Nyingchi-Lhasa Railway in China [18].

occurrence of multiple rockbursts, the depth of tunnel wall failure gradually increases, which is consistent with the gradual development of $\mathrm{V}$-shaped rockburst pits from the tunnel wall to the interior of the rock. Figure 21 shows several local rockbursts encountered in the NyingchiLhasa Tunnel: the depth and range of surrounding rock fracture increase after several local rockbursts, indicating that a local rockburst can be composed of several bursts. Therefore, the detailed formation process of the panshaped and V-shaped rockburst pits obtained in the present research, as well as the understanding of the relationship between them in the formation process, is of certain scientific value and can better reveal the formation process of strain-type rockbursts in tunnels.

\section{Conclusions}

(1) There are two types of rockburst pits in the rockburst band: pan-shaped and V-shaped, and the two types of rockburst pits can appear symmetrically or asymmetrically on the left and right sidewalls of the circular hole.

(2) Two types of cracks are generated in the left and right sidewalls of the circular hole: cracks parallel to and 
perpendicular to the principal stress, and the depth and width of rockburst pits are determined by cracks parallel to and perpendicular to the principal stress, respectively.

(3) Cracks parallel to the principal stress affect the type of rockburst pit; if a main crack parallel to the principal stress is formed in the sidewall, a panshaped rockburst pit is more likely; otherwise, a $\mathrm{V}$-shaped rockburst pit will be produced.

(4) There is a correlation between the formation process of the two types of rockburst pits. During the formation of a V-shaped rockburst pit, several rockbursts occur, and each rockburst forms a pan-shaped rockburst pit. In the process of developing from the tunnel wall to the deep rock, the width of the panshaped rockburst pit gradually decreases, and a $\mathrm{V}$-shaped rockburst with a stepped upper and lower boundary is formed.

\section{Data Availability}

The underlying data supporting the results of this study are included within the manuscript.

\section{Conflicts of Interest}

The authors declare that they have no conflicts of interest.

\section{Acknowledgments}

This work was supported by the National Natural Science Foundation of China (Nos. 51774138, 51804122, and 51904105), the Natural Science Foundation of Hebei Province (No. E2017209241), and the Supporting Plan for 100 Excellent Innovative Talents in Colleges and Universities of Hebei Education Department (No. SLRC2017050).

\section{References}

[1] M. He, L. R. E. Sousa, T. Miranda, and G. Zhu, "Rockburst laboratory tests database-application of data mining techniques," Engineering Geology, vol. 185, pp. 116-130, 2015.

[2] X. T. Feng, B. R. Chen, H. J. Ming et al., "Evolution law and mechanism of rockbursts in deep tunnels: Immediate rockburst," Chinese Journal of Rock Mechanics and Engineering, vol. 31, no. 3, pp. 433-444, 2012.

[3] B. R. Chen, X. T. Feng, H. J. Ming et al., "Evolution law and mechanism of rockburst in deep tunnel: Time-delayed rockburst," Chinese Journal of Rock Mechanics and Engineering, vol. 31, no. 3, pp. 561-569, 2012.

[4] W. D. Zhang and T. H. Ma, "Research on characteristic of rock burst and rules of micro seismic monitoring at diversion tunnels in Jinping II hydropower station," Chinese Journal of Rock Mechanics and Engineering, vol. 33, no. 2, pp. 339-348, 2013.

[5] C. Y. Liu, H. J. Li, and Y. Wu, "Mechanical mechanism and active control technology of rockbursts in Kamchik tunnel," Chinese Journal of Rock Mechanics and Engineering, vol. 39, no. 5, pp. 961-970, 2020.

[6] M. Lee and B. Haimson, "Laboratory study of borehole breakouts in Lac du Bonnet granite: a case of extensile failure mechanism," International Journal of Rock Mechanics and Mining Sciences \& Geomechanics Abstracts, vol. 30, no. 7, pp. 1039-1045, 1993.

[7] F.-q. Gong, Y. Luo, X.-b. Li, X.-f. Si, M. Tao, and T. Ming, "Experimental simulation investigation on rockburst induced by spalling failure in deep circular tunnels," Tunnelling and Underground Space Technology, vol. 81, pp. 413-427, 2018.

[8] G. S. Su, J. Q. Jiang, X. T. Feng, C. Mo, and Q. Jiang, "Experimental study of ejection process in rockburst," Chinese Journal of Rock Mechanics and Engineering, vol. 35, no. 10, pp. 1990-1999, 2016.

[9] H. Zhao, C. Liu, G. Huang, B. Yu, Y. Liu, and Z. Song, "Experimental investigation on rockburst process and failure characteristics in trapezoidal tunnel under different lateral stresses," Construction and Building Materials, vol. 259, p. 119530, 2020.

[10] X. B. Wang and Y. S. Pan, "Numerical simulation of rockburst processes of a circular tunnel at different lateral pressure coefficients," Rock and Soil Mechanics, vol. 31, no. 6, pp. 1937-1942, 2010.

[11] X. B. Wang, Y. S. Pan, and W. Wang, "Numerical simulation of rockburst processes of a circular tunnel at different confining pressures," Journal of Disaster Prevention and Mitigation Engineering, vol. 29, no. 6, pp. 597-603, 2009.

[12] L. Wang, M. C. Liao, J. H. Yang, D. H. Rui, and Q. Gao, "Numerical study on strain energy release mechanism of rockburst in tunnel," Journal of the China Railway Society, vol. 34, no. 1, pp. 109-114, 2012.

[13] X. B. Wang, X. L. Wu, and Y. S. Pan, "Modeling of the energy release during the shear band formation in the circular tunnel surrounding rock," Chinese Journal of Underground Space and Engineering, vol. 10, no. 1, pp. 43-50, 2014.

[14] P. Chirste, P. Turberg, V. Labiouse, R. Meulic, and A. Parriauxa, “An X-ray computed tomography-based index to characterize the quality of cataclastic carbonate rock samples," Engineering Geology, vol. 117, no. 3-4, pp. 180-188, 2011.

[15] L. C. Jia, M. Chen, L. T. Sun et al., "Experimental study on propagation of hydraulic fracture in volcanic rocks using industrial CT technology," Petroleum Exploration and Development, vol. 40, no. 3, pp. 405-408, 2013.

[16] X. Si and F. Gong, "Strength-weakening effect and sheartension failure mode transformation mechanism of rockburst for fine-grained granite under triaxial unloading compression," International Journal of Rock Mechanics and Mining Sciences, vol. 131, Article ID 104347, 2020.

[17] P. Liang, Y. B. Zhang, B. Z. Tian, X. L. Yao, L. Sun, and $\mathrm{X}$. X. Liu, "Experimental study on energy evolution characteristics in the process of tunnel rockburst," Chinese Journal of Rock Mechanics and Engineering, vol. 38, no. 4, pp. 736-746, 2019.

[18] X. Hu, G. Su, G. Chen et al., "Experiment on rockburst process of borehole and its acoustic emission characteristics," Rock Mechanics and Rock Engineering, vol. 52, no. 3, pp. 783-802, 2019.

[19] F. Q. Gong, X. F. Si, X. B. Li, and S. Y. Wang, "Experimental investigation of strain rockburst in circular caverns under deep three-dimensional high-stress conditions," Rock Mechanics and Rock Engineering, vol. 52, no. 4, pp. 1459-1474, 2019.

[20] G. S. Su, G. Y. Chen, X. C. Hu, S. M. Mei, and X. H. Huang, "Experimental study on influence of granite grain size on rockburst," Explosion and Shock Waves, vol. 39, no. 12, pp. 66-77, 2019. 
[21] C. Zhang, X.-T. Feng, H. Zhou, S. Qiu, and W. Wu, "Case histories of four extremely intense rockbursts in deep tunnels," Rock Mechanics and Rock Engineering, vol. 45, no. 3, pp. 275-288, 2012.

[22] M. C. He, D. Q. Liu, W. L. Gong et al., "Development of a testing system for impact rockbursts," Chinese Journal of Rock Mechanics and Engineering, vol. 39, no. 9, pp. 1729-1739, 2014.

[23] F. Q. Gong, Y. Luo, X. F. Si, and X. B. Li, "Experimental modelling on rockburst in deep hard rock circular tunnels," Chinese Journal of Rock Mechanics and Engineering, vol. 36, no. 7, pp. 1634-1648, 2017.

[24] N. C. Gay, "Fracture growth around openings in large blocks of rock subjected to uniaxial and biaxial compression," International Journal of Rock Mechanics and Mining Sciences \& Geomechanics Abstracts, vol. 13, no. 8, pp. 231-243, 1976.

[25] M. A. Lotidis, P. P. Nomikos, and A. I. Sofianos, "Numerical study of the fracturing process in marble and plaster hollow plate specimens subjected to uniaxial compression," Rock Mechanics and Rock Engineering, vol. 52, no. 11, pp. 43614386, 2019.

[26] E. Hoek, "Rock fracture around mining excavations," in Proceedings of the 4th International Conference on Stratigraphic Control \& Rock Mechanics, pp. 334-348, New York, NY, USA, January 1964.

[27] A. R. Ingraffea, "The strength ratio effect in the fracture of rock structures," in Proceedings of the 20th US Symposium on Rock Mechanics (USRMS), pp. 153-169, Austin, USA, January 1979.

[28] B. J. Carter, E. Z. Lajtai, and A. Petukhov, "Primary and remote fracture around underground cavities," International Journal for Numerical and Analytical Methods in Geomechanics, vol. 15, no. 1, pp. 21-40, 1991.

[29] B. J. Carter, J. Bruce, E. Z. Lajtai, and Y. G. Yuan, "Tensile fracture from circular cavities loaded in compression," International Journal of Fracture, vol. 57, no. 3, pp. 221-236, 1992.

[30] A. Y. Ma, F. Q. Wu, P. Sha, F. Zhao, and B. C. Sheng, "Progressive failure of Jinping marble in true triaxial rockburst test," Rock and Soil Mechanics, vol. 35, no. 10, pp. 2868-2874, 2014.

[31] J. A. Ryder, "Excess shear stress in the assessment of geologically hazardous situations," Journal of the South African Institute of Mining and Metallurgy, vol. 88, no. 1, pp. 27-39, 1988.

[32] H. Zhou, F. Z. Meng, C. Q. Zhang, J. J. Lu, and R. C. Xu, "Effect of structural plane on rockburst in deep hard rock tunnels," Chinese Journal of Rock Mechanics and Engineering, vol. 34, no. 4, pp. 720-727, 2015.

[33] P. Jia and W.-c. Zhu, "Dynamic-static coupling analysis on rockburst mechanism in jointed rock mass," Journal of Central South University, vol. 19, no. 11, pp. 3285-3290, 2012.

[34] C. Zhang, X.-T. Feng, H. Zhou, S. Qiu, and W. Wu, "Rockmass damage development following two extremely intense rockbursts in deep tunnels at Jinping II hydropower station, Southwestern China," Bulletin of Engineering Geology and the Environment, vol. 72, no. 2, pp. 237-247, 2013.

[35] Z. S. Hou, Q. M. Gong, and Z. H. Sun, "Primary failure types and their failure mechanisms of deep buried and intact marble at Jinping II hydropower station," Chinese Journal of Rock Mechanics and Engineering, vol. 30, no. 4, pp. 727-732, 2011. 